\title{
Design and Synthesis of 16-Membered Cyclopeptides Active Against Vancomycin-resistant Enterococci (VRE)
}

\author{
Jieping Zhu*
}

\begin{abstract}
The design, synthesis and antibiotic activities of the modified carboxylate binding pocket (D-O-E ring) of vancomycin (1) are summarized in this short account. The preliminary structure-activity relationship (SAR) studies indicated that both the structure of the 16-membered macrocycle including the absolute configuration of the modified AA4 unit and the presence of a hydrophobic chain were important for anti-VRE activities of these series of synthetic analogues. Compounds $9 \mathrm{c}$ and $9 \mathrm{~d}$ in which the central amino acid (AA4) of vancomycin was replaced by $(2 R, 3 R)$ - $\alpha$-hydroxy- $\beta$-amino acid and $(2 R, 3 R)-\alpha, \beta$-diamino acid, respectively, were found to be useful templates in searching for active compounds against both vancomycin-sensitive and -resistant strains. Two of these compounds (16d and $\mathbf{1 6 n}$ ) having an elongated peptide chain at the $C$-terminal were found to be active against a broad spectrum of both vancomycin-sensitive (Staphylococcus aureus) and -resistant strains (E. faecium, E. faecalis).
\end{abstract}

Keywords: Antibiotic $\cdot$ Cyclopeptide $\cdot$ Macrocycle $\cdot S_{N} A r$ reaction $\cdot$ Vancomycin

\section{Introduction}

Vancomycin (1) is a glycosylated non-ribosomal peptide produced by the Actinobacteria species Amycoplatopsis orientalis. The side chain of haptapeptide aglycon was oxidatively linked via two endo aryl-aryl ether and one endo aryl-aryl bond creating an interconnected strained tricyclic ring system. ${ }^{[1]}$ It is a rare halogen-containing natural product that contains three elements of chirality: central chirality, planar chirality and axial chirality. Isolated in 1953 by scientists at Eli Lilly, vancomycin was marketed in 1958 long before its structure and mode of action had been fully determined. For many years since its initial use, vancomycin was one of the few antibiotics of last resort for the treatment of infections due

${ }^{*}$ Correspondence: Prof. J. Zhu

Laboratory of Synthesis and Natural Products Institute of Chemical Sciences and Engineering Ecole Polytechnique Fédérale de Lausanne EPFL-SB-ISIC-LSPN, CH-1015 Lausanne E-mail: jieping.zhu@epfl.ch to methicillin-resistant Staphylococcus aureus (MRSA) and other Gram-positive organisms in patients allergic to $\beta$-lactam antibiotics. ${ }^{[1]}$ Unfortunately, resistance to vancomycin appeared in the late 1980s and the frequency of resistance has increased significantly over the past decades. Since vancomycin-resistant enterococci (VRE) carries resistance to virtually all other known antibiotics, it represents a serious threat to public health. ${ }^{[2]}$ To make things even worse, in vitro experiment has shown that such resistance is transferable to Staphylococci. ${ }^{[3]}$

Vancomycin acts by binding to D-alanyl-D-alanine (D-Ala-D-Ala) of the peptidoglycan precursors, blocking therefore the final stages of the peptidoglycan synthesis. This mode of action takes place at the cell surface avoiding therefore some common cellular resistance mechanisms such as efflux pumps and bacterial modification. Bacteria become resistant to vancomycin by reprogramming of the peptidoglycan termini from D-Ala-D-Ala dipeptide to D-Ala-D-Lact (D-alanyl-D-lactate) depsipeptide that binds only weakly to the drug. ${ }^{[4]}$ In fact, in vitro binding studies have shown that the affinity of vancomycin for $\mathrm{N}$-Ac-D-Ala-D-Lact is about 1000 times weaker than its affinity for $N$-Ac-D-Ala-DAla, due to one missing hydrogen bond and the ground state repulsion between the two oxygen lone-pairs in the former complex. The reduced binding affinity translated into about 1000-fold reduced sensitivity of vancomycin-resistant bacteria to this drug (Fig. 1).[5]

The emergence of vancomycin resis-

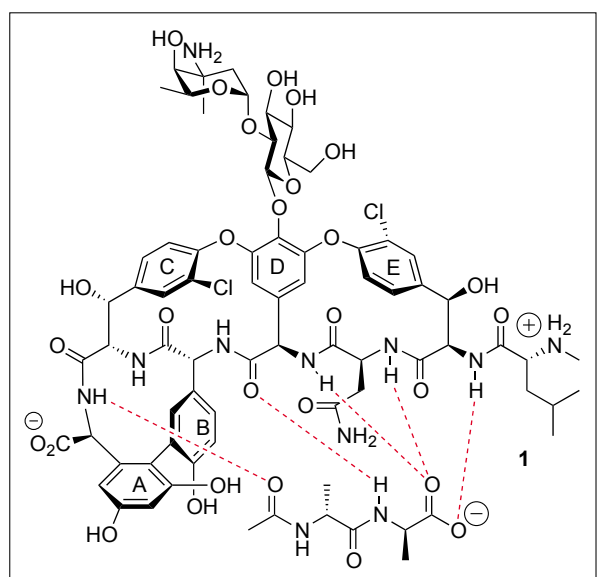

Fig. 1. Hydrogen bonding network of vancomycin (1) and N-Ac-D-Ala-D-Ala.

tance provided an incentive for the discovery and development of new antibiotics that would be active against both sensitive and resistant strains of enterococci. Since vancomycin is readily available by fermentation technology, many efforts have been dedicated to the structural modification of natural glycopeptides. Extensive structure-activity relationship (SAR) studies of semisynthetic derivatives led to the development of one marketed drug (telavancin, 2) ${ }^{[6]}$ and two drug candidates, oritavancin (LY333328, 3) ${ }^{[7]}$ and the dalbavancin (4, Fig. 2). ${ }^{[8]}$ In addition, other structurally unrelated compounds such as Synercid (a 3/7 mixture of quinopristin $\mathbf{5}$ and dalfopristin 6), ${ }^{[9]}$ linezolide (7), ${ }^{[10]}$ and daptomycin $(\mathbf{8}$, Fig. 3) ${ }^{[11]}$ have been developed and marketed for the treatment of vancomycin-resistant infections. 


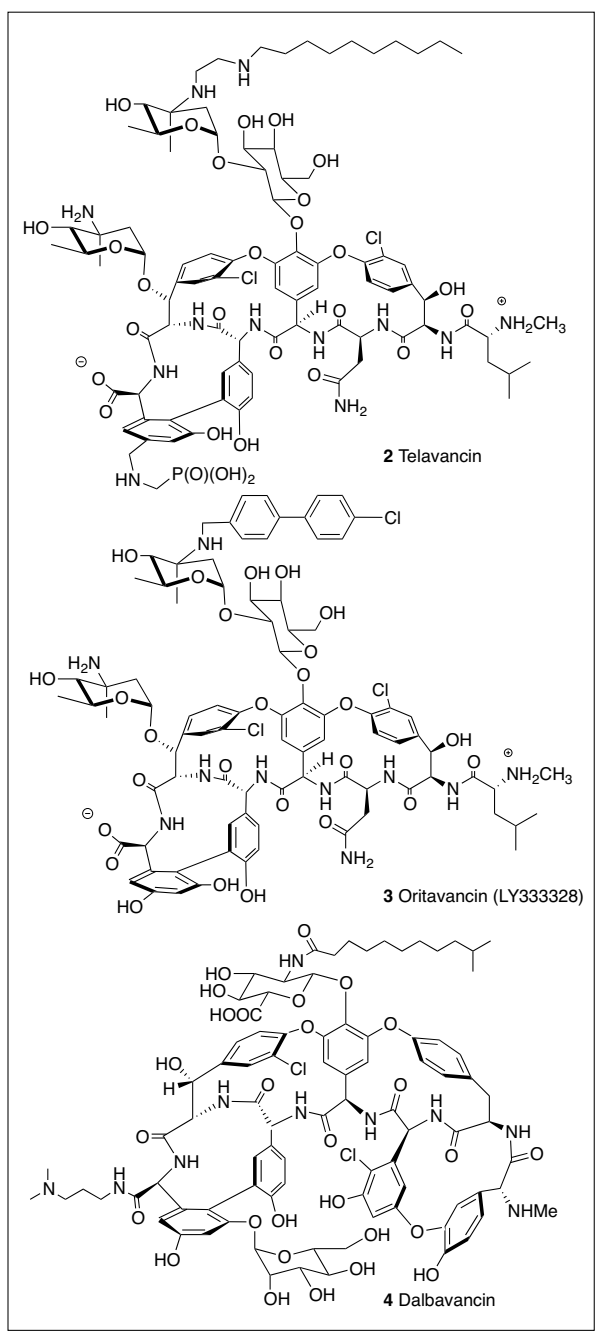

Fig. 2. Semi-synthetic glycopeptide antibiotics.

\section{Molecule Design Aiming at Reversing Vancomycin Resistance}

The 16-membered D-O-E ring is the binding pocket of vancomycin since attractive electrostatic interactions (charged ammonium salt and carboxylate) and four out of five $\mathrm{H}$-bonds formed between vancomycin and $N$-Ac-D-Ala-D-Ala reside in the peptide backbone of this $m, p$-cyclophane. To evaluate the minimum structural requirement of vancomycin against both sensitive and resistant strains of $e n$ terococci, we became interested in the general structure 9[12] (Fig. 4) in which the carboxylate binding pocket of vancomycin is modified following two guidelines: a) replacing the carbonyl group of central amino acid (AA4) of vancomycin by $O H C H C O R$ or $P H N C H C O R$. It was expected that this structural modification can, a priori, lead to a modified D-O-E ring with increased affinity toward $\mathrm{N}$-AcD-Ala-D-Lact by restoring the missing hydrogen bond and by avoiding the unfavorable electronic repulsion found in the vancomycin/D-Ala-D-Lact complex; ${ }^{[13]}$ b) introducing a hydrophobic chain or a

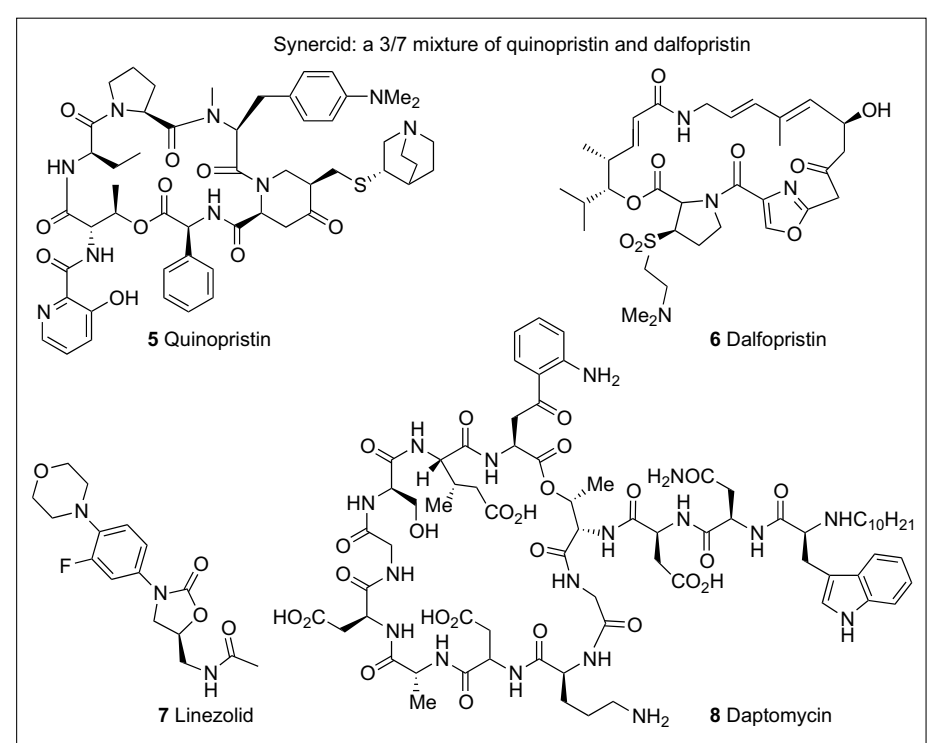

Fig. 3. Drugs active against VRE.

sugar moiety at the appropriate position of the modified D-O-E ring. It is known that introducing a hydrophobic chain into the sugar part of vancomycin can produce compounds that are capable of reversing the drug-resistance ( $c f$ telavancin (2) and the oritavancin (3), Fig. 2). This is surprising at first glance since this subunit is not directly involved in substrate binding. Indeed, in vitro activity of oritavancin did not parallel with its binding affinity with D-Ala-D-Lact. Two theories have been proposed to account for oritavancin's bioactivity against VRE. [1] Williams hypothesized that the presence of a lipid chain in the disaccharide part of vancomycin enhanced avidity for D-Ala-D-Lact by facilitating membrane anchoring and/or by promoting dimerization. ${ }^{[14]}$ Kahne advanced that oritavancin acts against VRE by direct interaction with the transglycosylase without substrate binding. ${ }^{[15]}$ It is worth noting that structural modification of the vancomycin-type glycopeptide is particularly challenging due to its structure complexity. ${ }^{[16]}$ Therefore, most of the chemical transformations reported to date have been localized on the periphery of the macrocycles relying on simple chemical reactions. Indeed, it would be extremely difficult, if not impossible, to chemically modify the carboxylate-binding pocket (D-O-E ring) of natural glycopeptides to include new hydrogen bond contacts with the modified peptidoglycan termini. ${ }^{[17]}$

\section{Synthesis of the Modified Carboxylate-binding Pocket}

Synthesis of 16-membered macrocycles 9a and 9b was accomplished as shown in Scheme 1. Coupling of the suitably protected $(2 S, 3 R)-\alpha$-hydroxy- $\beta$-amino acid $\mathbf{1 0}^{[18]}$ with tripeptide 11 (EDC, HOBt) afforded tetrapeptide $\mathbf{1 2}$ in excellent yield. Treatment of 12 with $\mathrm{BCl}_{3}$ led to the simultaneous deprotection of the isopropyl ether, the tert-butyldimethylsilyl ether and the $N$-Boc function. Re-protection of the terminal amine in the form of $\mathrm{N}$-Boc furnished phenol $\mathbf{1 3}$ in $81 \%$ yield over two steps. The key intramolecular $\mathrm{S}_{\mathrm{N}}$ Ar-based cycloetherification of $\mathbf{1 3}$ was best performed in DMSO $(c 0.01 \mathrm{M})$ in the presence of $\mathrm{CsF}$ at room temperature. ${ }^{[19]}$ Under these conditions, the desired 16-membered $m, p$-cyclophane was formed as a mixture of two separable atropisomers $9 \mathbf{a}$ and $\mathbf{9 b}$ in $72 \%$ overall yield (ratio $\mathbf{9 a} / \mathbf{9 b}=3 / 1$ ).

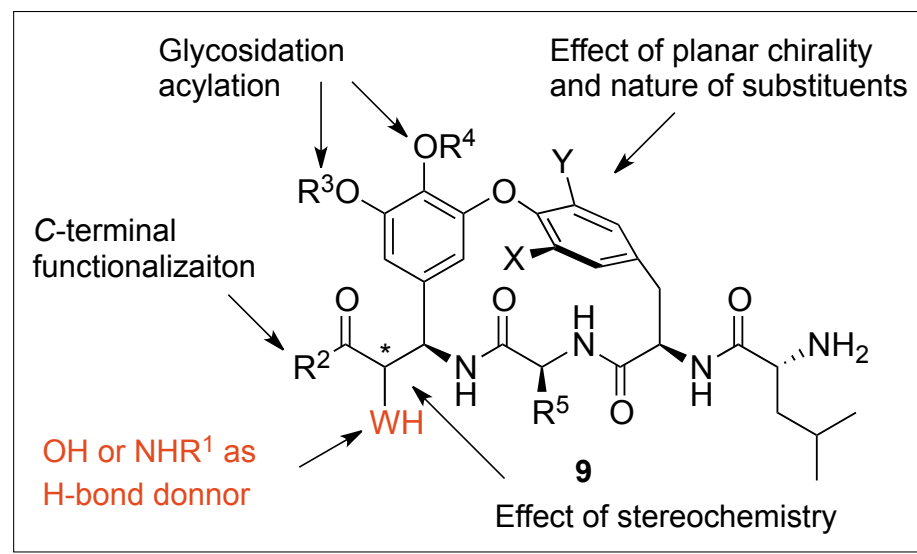

Fig. 4. Modified vancomycin carboxylate-binding pocket: restoring the missing $\mathrm{H}$-bond with D-AlaD-Lact. 


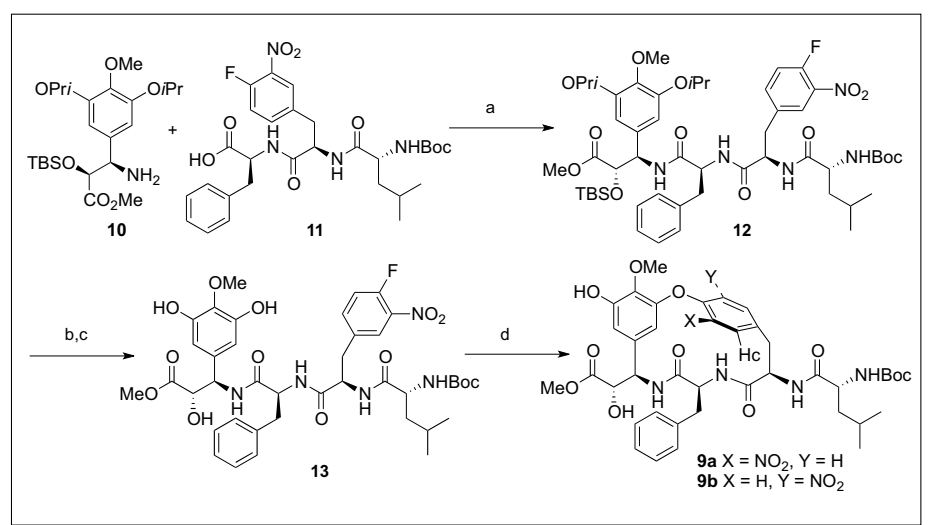

Scheme 1. Synthesis of 16-membered macrocycles $9 \mathbf{a}$ and 9b: a) EDC, HOBt, $\mathrm{CH}_{2} \mathrm{Cl}_{2}, 25^{\circ} \mathrm{C}, 12 \mathrm{~h}$ $89 \%$; b) $\mathrm{BCl}_{3}, \mathrm{CH}_{2} \mathrm{Cl}_{2}$, $0{ }^{\circ} \mathrm{C}, 1 \mathrm{~h}$; then $\mathrm{MeOH}$; c) $\mathrm{Boc}_{2} \mathrm{O}, \mathrm{NaHCO}_{3}$, dioxane/ $\mathrm{H}_{2} \mathrm{O}(2 / 1)$, $25^{\circ} \mathrm{C}, 12 \mathrm{~h}, 81 \%(2$ steps); d) CsF, DMSO, $25{ }^{\circ} \mathrm{C}, 16 \mathrm{~h}, 72 \%$.

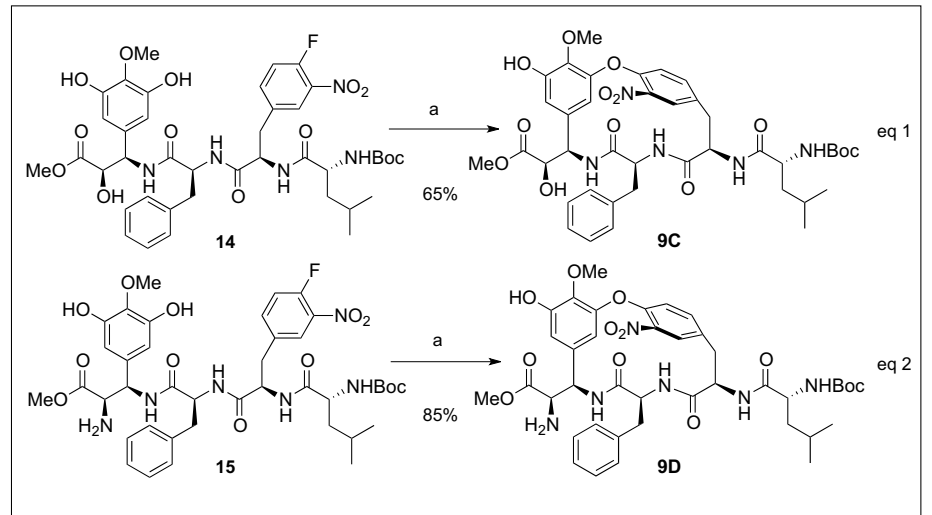

The linear tetrapeptide $\mathbf{1 4}$ containing a $(2 R, 3 R)$ - $\alpha$-hydroxy- $\beta$-amino acid unit was synthesized following the same synthetic route as described for 13. Interestingly, intramolecular $\mathrm{S}_{\mathrm{N}} \mathrm{Ar}$ reaction of $\mathbf{1 4}(\mathrm{CsF}$, DMSO, $25^{\circ} \mathrm{C}, 16 \mathrm{~h}$ ) afforded only one atropdiastereomer 9c in $65 \%$ yield (Eqn. 1, Scheme 2). The high diastereoselectivity observed in the cycloetherification of $\mathbf{1 4}$ relative to 13 was difficult to rationalize, but was in accord with the previous observation that the atropdiastereoselectivity of this reaction is highly substrate-dependent. ${ }^{[20]}$ The macrocycle 9d having an amino function was similarly synthesized (Eqn. 2, Scheme 2). It is worth noting that in the latter case, the alternative cyclization mode with primary amine acting as nucleophile was not observed.[21]

From compounds 9a-9d, a series of derivatives 16 were synthesized and some representative examples are shown in Fig. 5.

The synthesis of compound $\mathbf{1 6 \mathbf { d }}$ is representative and is summarized in Scheme 3. Selective glycosylation of phenol was realized by reaction of $\mathbf{9 c}$ with freshly prepared 3,4,6-tri- $O$-acetyl-2- $N$-lauroyl-2-amino-2deoxy- $\alpha$-D-glucopyranosyl bromide (17)

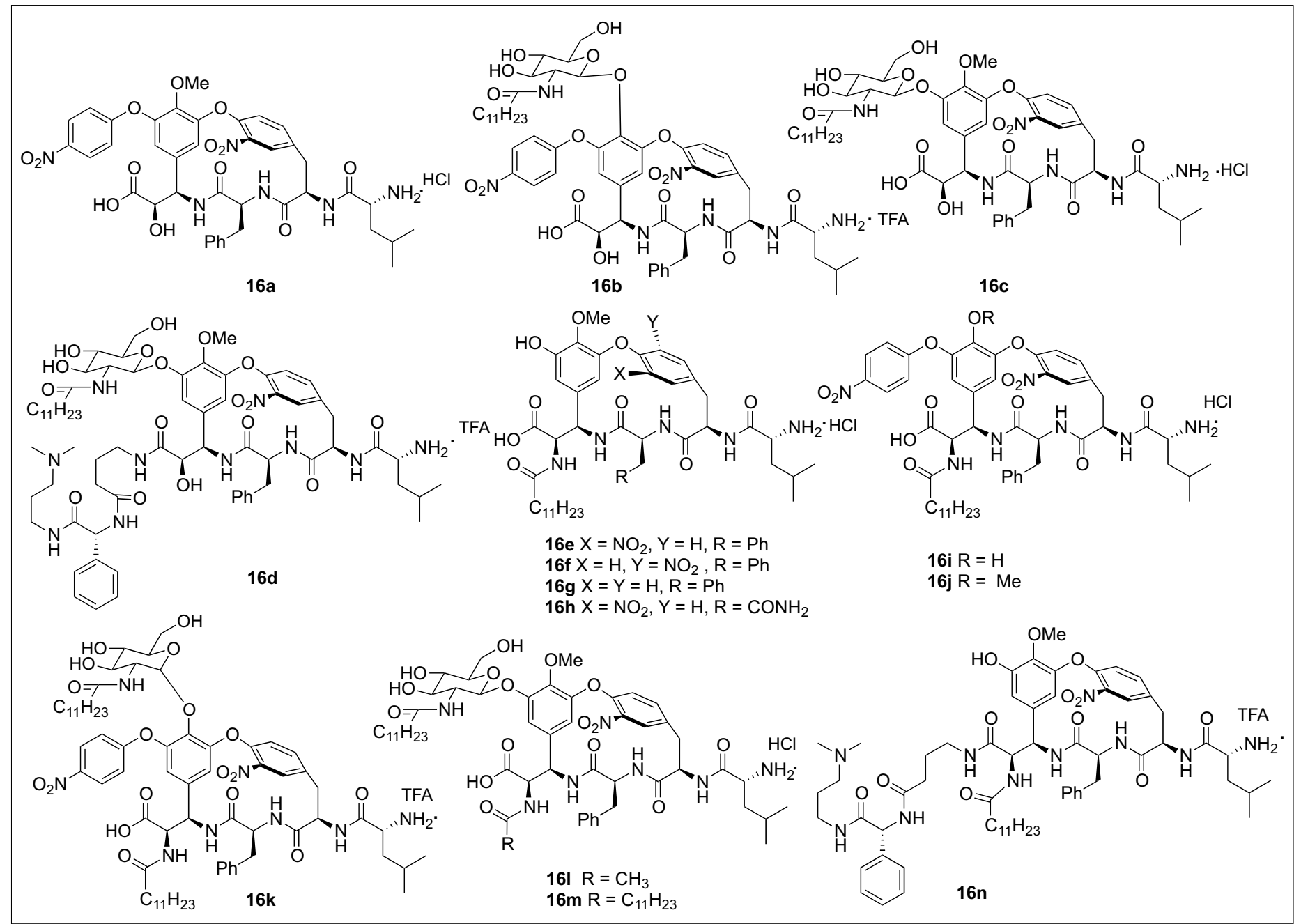

Fig. 5. Structures of macrocycles 16a-16n. 


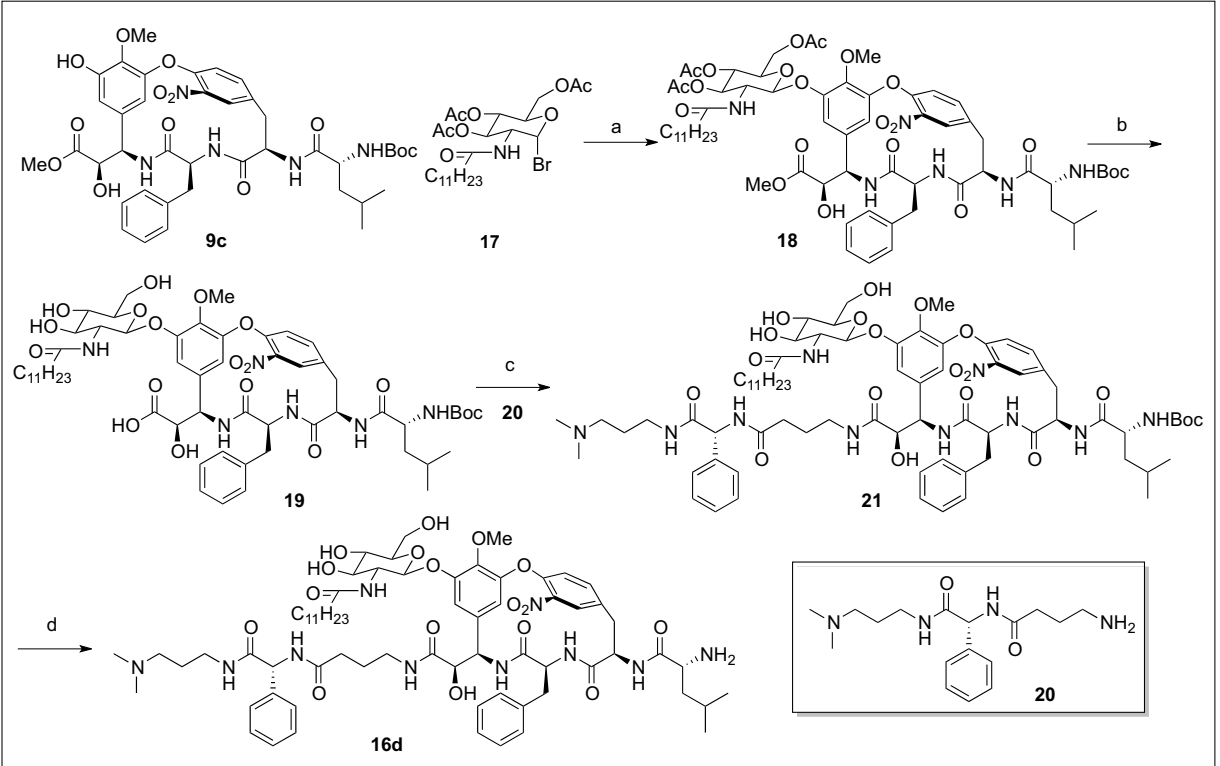

Scheme 3. Synthesis of compound 16d: a) (nBu) $\mathrm{NHSO}_{4}, 10 \%$ aqueous $\mathrm{Na}_{2} \mathrm{CO}_{3} / \mathrm{CH}_{2} \mathrm{Cl}_{2}(1 / 1)$, $25^{\circ} \mathrm{C}, 4 \mathrm{~h}, 76 \%$; b) $\mathrm{LiOH}, \mathrm{THF} / \mathrm{H}_{2} \mathrm{O}(3: 1), 0{ }^{\circ} \mathrm{C}, 4 \mathrm{~h}, 62 \%$; c) $20, \mathrm{EDC}, \mathrm{HOBt}, \mathrm{CH}_{2} \mathrm{Cl}_{2}, 25^{\circ} \mathrm{C}, 12 \mathrm{~h}$, $34 \%$; d) TFA, $\mathrm{CH}_{2} \mathrm{Cl}_{2}, 0^{\circ} \mathrm{C}, 1 \mathrm{~h}, 75 \%$.

under mild phase-transfer conditions (10\% aqueous $\mathrm{Na}_{2} \mathrm{CO}_{3}, n \mathrm{Bu}_{4} \mathrm{NHSO}_{4}, \mathrm{CH}_{2} \mathrm{Cl}_{2}$, rt). ${ }^{[22]}$ Treatment of $\mathbf{1 8}$ with lithium hydroxide $\left(\mathrm{LiOH}, \mathrm{THF}-\mathrm{H}_{2} \mathrm{O}\right)$ removed both the methyl ester and three acetate functions to provide the hydroxy acid 19. Coupling of 19 with amine 20 (EDC, $\mathrm{HOBt}, \mathrm{CH}_{2} \mathrm{Cl}_{2}$ ) provided 21, which upon $\mathrm{N}$-deprotection, afforded the desired compound 16d in $75 \%$ yield. Compound 16d having an elongated $C$-terminal was designed with the aim to introduce an additional hydrogen bond with the peptidoglycan termini (Fig. 6).

\section{Antibiotic Activities of Synthetic Compounds 16}

Minimum inhibitory concentrations for these compounds as well as reference compounds (vancomycin, teicoplanin, Synercid $^{\circledR}$, and daptomycin) are measured using a standard microdilution assay. ${ }^{[23]}$ Selected results are summarized in Table 1.

Compounds derived from $9 \mathbf{a}$ and $\mathbf{9 b}$ having an external $S$-configured secondary hydroxy group (structure not shown) were found to be inactive against both vancomy-

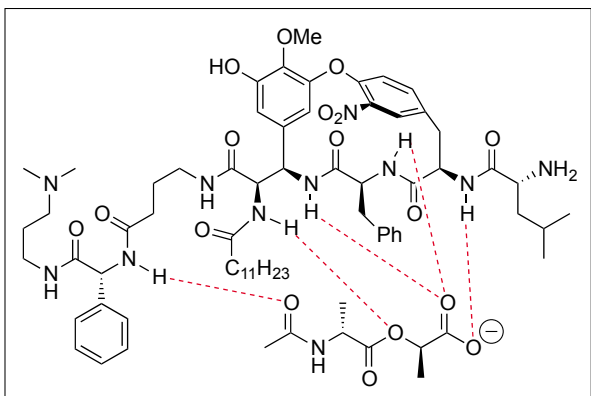

Fig. 6. Hypothetic H-bond network between 16d and $N$-Ac-D-Ala-D-Lact. fBacterial strain L613 clin. isolate Met-R. cin-sensitive and -resistant strains, regardbioactivities. The parent compound was inactive, but its $O$-arylated derivatives $\mathbf{1 6 a}$ inhibited the growth of E faecalis Van A at reasonably low MIC values (Table 1, entry 1$)$. More interestingly, $O$-glycosylated derivatives $16 \mathbf{b}$ and especially $16 \mathbf{c}$ displayed potent activities against VRE (entries 2, 3). Furthermore, compound 16d having an elongated peptide chain at the $C$-terminal was active not only against VRE, but also against vancomycin-sensitive Staphylococcus aureus (entry 4).

The bioactivity of compounds derived from 9d depended very much on the nature of the functional group attached to the $\mathrm{C}_{\alpha}$ amino group. Thus, neither the parent compounds, nor its $N, N$-dimethylated derivative (structure not shown), were active against VRE. Whereas $N$-acetyl derivative $\mathbf{1 6}$ is poorly active (entry 12), the lauroyl $(N$-dodecanoyl) amides 16e and 16f displayed interesting activities against VRE (entries 5, 6), indicating the important role of a hydrophobic chain. Compound 16h (entry 8) having an asparagine unit in the $i+2$ position, was slightly less active than 16e having a phenylalanine (entry 5). Planar chirality plays only a minor effect on the bioactivity since the potency of 16e and 16f is comparable (entries 5 vs 6 ). However, the presence of the nitro group at the E ring is beneficial since $\mathbf{1 6 g}$, being devoid of this group, was much less active (entry 7). The activity against VRE remained essentially unchanged upon ben-

Table 1. MICs $(\mathrm{mg} / \mathrm{mL})$ of selected macrocycles and reference compounds ${ }^{\mathrm{a}}$

\begin{tabular}{|c|c|c|c|c|c|c|}
\hline \multirow[t]{2}{*}{ Entry } & \multirow[t]{2}{*}{ Cmpd. } & \multicolumn{2}{|c|}{ E. faecium } & \multicolumn{2}{|c|}{ E. faecalis } & \multirow{2}{*}{$\begin{array}{r}\text { Staph } \\
\text { aureus }^{f}\end{array}$} \\
\hline & & sensitive $^{b}$ & resistant ${ }^{\mathrm{C}}$ & sensitive $^{d}$ & resistant $\mathrm{t}^{\mathrm{e}}$ & \\
\hline 1 & $16 \mathbf{a}$ & 128 & 128 & 16 & 16 & $>128$ \\
\hline 2 & $16 b$ & 128 & 128 & 64 & 32 & $>128$ \\
\hline 3 & $16 c$ & 64 & 32 & 8 & 8 & 128 \\
\hline 4 & 16d & 16 & 8 & 16 & 8 & 32 \\
\hline 5 & $16 e$ & 128 & 8 & 4 & 4 & 64 \\
\hline 6 & $16 f$ & 128 & 16 & 8 & 8 & $>128$ \\
\hline 7 & $16 \mathrm{~g}$ & $>128$ & 128 & 128 & 128 & $>128$ \\
\hline 8 & $16 h$ & $>128$ & 128 & 16 & 8 & 64 \\
\hline 9 & $16 \mathbf{i}$ & 128 & 128 & 4 & 4 & $>128$ \\
\hline 10 & 16j & 128 & 128 & 4 & 2 & $>128$ \\
\hline 11 & $16 k$ & $>128$ & $>128$ & 8 & 8 & \\
\hline 12 & 161 & 1024 & 1024 & 64 & 64 & $>1024$ \\
\hline 13 & $16 \mathrm{~m}$ & 128 & 32 & 8 & 8 & $>256$ \\
\hline 14 & $16 n$ & 8 & 8 & 8 & 8 & 16 \\
\hline 15 & vancomycin & 2 & $>128$ & 1 & $>128$ & 1 \\
\hline 16 & teicoplanin & 0.5 & $>128$ & 0.125 & 64 & 1 \\
\hline 17 & synercid & 4 & 4 & 4 & 8 & 81 \\
\hline 18 & daptomycin & 32 & 16 & 4 & 8 & 2 \\
\hline
\end{tabular}

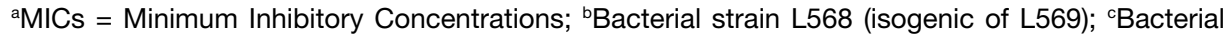

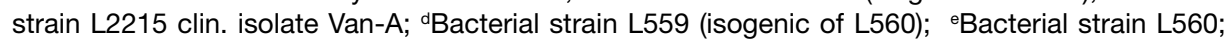

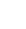


zylation and glucosylation of the phenol function. As in the case of the $\mathrm{OH}$ series, compound 16n (entry 14) having an elongated peptide chain at the $C$-terminal is active against a broad spectrum of both vancomycin-sensitive (Staphylococcus aureus) and -resistant strains.

It is noteworthy that some of these simple macrocycles are more active, in vitro, against VRE than most of the vancomycin and teicoplanin derivatives reported in the literature and are almost as active as Synercid $^{\circledR}$, a clinically used drug for combating VRE. The generic structure 9 was originally designed with the hope to restore the missing hydrogen bond with the D-Ala-D-lact depsipeptide by switching the amide carbonyl (hydrogen-bond acceptor) of vancomcyin's fourth amino acid into a hydroxy group (hydrogen-bond donor). Although interesting activities against VRE were indeed found for some of these derivatives, substrate binding cannot account for their antibiotic activities for the following reasons: a) attempts to measure the binding affinity between $\mathbf{1 6 c}$ and $N$-Ac-D-Ala-D-Ala as well as $\mathbf{1 6 c}$ and $N$-Ac-D-Ala-D-Lact by either UV absorption or by NMR titration (in DMSO) failed to provide any exploitable results, most probably due to the low receptor-substrate affinities; b) the observed hydrophobic effect is apparently not due to the simple increase of effective molarity resulting from membrane anchoring. Rather it was specific, as no beneficial effect was observed when the same aliphatic chain was introduced to the E-ring of the molecule (structure not shown). This result can be better explained on the basis of a specific interaction between the macrocycle and the target enzymes. Overall and in accord with Kahne's observation, [15] we hypothesize that these compounds might have a direct interaction with proteins critical for VRE cell-wall biosynthesis although a detailed mechanism of action remains to be investigated.

In conclusion, a modified vancomycin binding pocket (D-O-E ring) has been designed and synthesized. The key structural features of this biaryl ether-containing macrocycle are: a) the incorporation of $\beta$-amino- $\alpha$-hydroxy acid or $\alpha, \beta$-diamino acid as the $C$-terminal component of the 16-membered cyclopeptide; b) the presence of a hydrophobic chain or lipidated aminoglucose at the appropriate position. The SAR studies indicated that a combination of a modified binding pocket with a suitably positioned hydrophobic chain constitutes a viable approach in the search for compounds active against VRE.

Received: September 14, 2013

[1] a) D. H. Williams, Nat. Prod. Report 1996, 469; b) J. Zhu, Expert. Opin. Ther. Pat. 1999, 9, 1005; c) K. C. Nicolaou, C. N. C. Boddy, S. Bräse, N. Winssinger, Angew. Chem. Int. Ed. 1999, 38, 2096; d) R. D. Süssmuth, ChemBioChem. 2002, 3, 295; e) D. Kahne, C. Leimkuhler, W. Lu, C. T. Walsh, Chem. Rev. 2005, 105, 425.

[2] B. K Hubbard, C. T. Walsh, Angew. Chem. Int. Ed. 2003, 42, 730 .

[3] M. N. Swartz, Proc. Natl. Acad. Sci. USA 1994, 91, 2420.

[4] D. H. Williams, B. Bardsley, Angew. Chem. Int. Ed. 1999, 38, 1172.

[5] a) R. K. Jain, J. Trias, J. A. Ellman, J. Am. Chem. Soc. 2003, 125, 8740; b) C. C. McComas, B. M. Crowley, D. L. Boger, J. Am. Chem. Soc. 2003, 125,$9314 ;$ c) J.-G. Lee, C. Sagui, C. Roland, J. Am. Chem. Soc. 2004, 126, 8384; d) X. Jie, A. Okano, J. G. Pierce, R. C. James, S. Stamm, C. M. Crane, D. L. Boger, J. Am. Chem. Soc. 2012, 134, 1284.

[6] C. S. Lunde, S. R. Hartouni, J. W. Janc, M. Mammen, P. P. Humphrey, B. M. Benton, Antimicrob. Agents Chemother. 2009, 53, 3375.

[7] http://ir.themedicinescompany.com/phoenix. zhtml?c $=122204 \& p=$ irol-newsArticle \&id $=1834647$

[8] http://en.wikipedia.org/wiki/Dalbavancin

[9] B. Pavan, Curr. Opin. Investig. Drugs 2000, 1, 173.

[10] M. R. Barbachyn, C. W. Ford, Angew. Chem. Int. Ed. 2003, 42, 2010.

[11] R. H. Baltz, Curr. Opin. Chem. Biol. 2009, 13, 144.

[12] a) N. Ma, Y. Jia, Z. Liu, E. Gonzalez-Zamora, M. Bois-Choussy, A. Malabarba, C. Brunati, J. Zhu, Bioorg. Med. Chem. Lett. 2005, 15, 743; b) Y. Jia, E. Gonzalez-Zamora, N. Ma, Z. Liu, M. Bois-Choussy, A. Malabarba, C. Brunati, J. Zhu, Bioorg. Med. Chem. Lett. 2005, 15, 4594; c) Y. Jia, M. Bois-Choussy, A. Malabarba, C. Brunati, J. Zhu, J. Antibiot. 2006, 59, 543; d) Y. Jia, N. Ma, Z. Liu, M. Bois-Choussy, E. Gonzalez-Zamora, A. Malabarba, C. Brunati, J. Zhu, Chem. Eur. J. 2006, 12, 5334.

[13] M. Bois-Choussy, L. Neuville, R. Beugelmans, J. Zhu, J. Org. Chem. 1996, 61, 9309.

[14] D. H. Williams, A. J. Maguire, W. Tsuzuki, M. S. Westwell, Science 1998, 280, 711.

[15] a) M. Ge, Z. Chen, H. R. Onishi, J. Kohler, L. L. Silver, R. Kerns, S. Fukuzawa, C. Thompson, D.
Kahne, Science 1999, 284, 507; b) U. S. Eggert, N. Ruiz, B. V. Falcone, A. A. Branstrom, R. C. Goldman, T. J. Silhavy, D. Kahne, Science 2001, 294, 361.

[16] Modification of vancomycin type glycopeptide antibiotics by reprogramming the biosynthesis pathway, see: a) S. Weist, C. Kittel, D. Bischoff, B. Bister, V. Pfeifer, G. J. Nicholson, W. Wohlleben, R. D. Süssmuth, J. Am. Chem. Soc. 2004, 126, 5942; b) P. C. Schmartz, K. Wölfel, K. Zerbe, E. Gad, E. S. El Tamany, H. K. Ibrahim, K. Abou-Hadeed, J. A. Robinson, Angew. Chem. Int. Ed. 2012, 51, 11468.

[17] By total synthesis, see: J. Xie, J. G. Pierce, R. C. James, A. Okano, D. L. Boger, J. Am. Chem. Soc. 2011, 133, 13946.

[18] Z. Liu, N. Ma, Y. Jia, M. Bois-Choussy, A. Malabarba, J. Zhu, J. Org. Chem. 2005, 70, 2847.

[19] a) R. Beugelmans, G. P. Singh, M. BoisChoussy, J. Chastanet, J. Zhu, J. Org. Chem. 1994, 59, 5535; b) b) J. Zhu, R. Beugelmans, S. Bourdet, J. Chastanet, G. Roussi, J. Org. Chem. 1995, 60, 6389; c) J. Zhu, J. P. Bouillon, G. P. Singh, J. Chastanet, R. Beugelmans, Tetrahedron Lett. 1995, 36, 7081; d) R. Beugelmans, A. Bigot, M. Bois-Choussy, J. Zhu, J. Org. Chem. 1996, 61, 771; e) K. Burgess, D. Lim, M. Bois-Choussy, J. Zhu, Tetrahedron Lett. 1997, 38, 3345; f) P. Cristau, J. P. Vors, J. Zhu, Org. Lett. 2001, 3, 4079; g) P. Cristau, J. P. Vors, J. Zhu, Tetrahedron 2003, 59, 7859; h) P. Cristau, J. P. Vors, J. Zhu, Tetrahedron Lett. 2003, 44, 5575; i) M. Bois-Choussy, P. Cristau, J. Zhu, Angew. Chem. Int. Ed. 2003, 42, 4238; j) Y. Jia, M. Bois-Choussy, J. Zhu, Angew. Chem. Int. Ed. 2008, 47, 4167; k) Z. H. Wang, M. BoisChoussy, Y. Jia, J. Zhu, Angew. Chem. Int. Ed. 2010, 49, 2018; 1) Q. Wang, J. Zhu, Chimia 2011, 65, 168 .

[20] a) For temperature-controlled atropdiastereoselective cycloetherification, see: R. Beugelmans, M. Bois-Choussy, C. Vergne, J.-P. Bouillon, J. Zhu, Chem. Commun. 1996, 1029 ; b) For designed substrate-controlled atropdiastereoselective cycloetherification, see: K. C. Nicolaou, C. N. C. Boddy, J. Am. Chem. Soc. 2002, 124, 10451; c) For an example of enantioselective cycloetherification, see: G. Islas-Gonzalez, M. Bois-Choussy, J. Zhu, Org. Biomol. Chem. 2003, 1, 30; d) For an earlier account, see: J. Zhu, Synlett 1997, 133.

[21] Synthesis of cyclopeptide alkaloids having an endo aryl-alkyl ether bond by intramolecular SNAr reaction, see: a) T. Temal-Laïb, J. Chastanet, J. Zhu, J. Am. Chem. Soc. 2002, 124,583 ; b) P. Cristau, T. Temal-Laïb, M. BoisChoussy, M. T. Martin, J. P. Vors, J. Zhu, Chem. Eur. J. 2005, 11, 2668.

[22] G. Islas-Gonzalez, J. Zhu, J. Org. Chem. 1999, $64,914$.

[23] The antibiotic activities of these compounds were measured by scientists at Vicuron Pharmaceuticals, Italy Research Center. 